\title{
Effective formation of Al-rich surface clays through highly acidic water activity on early Mars
}

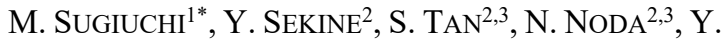 \\ TAKAHASHI ${ }^{3}$, AND R. RAMIREZ ${ }^{2}$ \\ ${ }^{1}$ Dept. Earth Planet. Sci., Tokyo Tech., 152-8550, Japan \\ (*correspondence: sugiuchi.m.aa@m.titech.ac.jp) \\ ${ }^{2}$ Earth-Life Sci. Inst., Tokyo Tech., Japan \\ ${ }^{3}$ Dept. Earth Planet. Sci., Univ. Tokyo, Japan \\ Introduction
}

Remote sencing observations have revealed a widespread occurrence of weathering profiles in the low-latitude regions of Mars [1]. The weathering profiles consist of Al-rich clays and sulfate minerals in the upper part and $\mathrm{Mg} / \mathrm{Fe}$-rich clay minerals in the lower part [2]. These secondary minerals would have been formed through water-rock reactions between basement rocks and infused surface water in early Hesperian [3]. Here, we perform laboratory experiments of chemical weathering using a flow-through type reactor to constrain the chemistry of surface water and duration of water-rock reactions on early Mars. To simulate chemical weathering on early Mars, we used two types of solution: One is pure water in dissolution equilibrium with 1 bar of $\mathrm{CO}_{2}$ $(\mathrm{pH} 4)$ and the other is sulfuric acid solution in dissolution equilibrium with 1 bar $\mathrm{CO}_{2}(\mathrm{pH} 1)$.

\section{Results and Discussion}

Our experimental results show that sulfuric acid surface water could effectively generate the weatheing profiles observed on Mars. Our results show that $\mathrm{pH}$ at the top of the reaction vessel is controlled as $\mathrm{pH} 2-3$ owing to the formation of sulfate mineral, where dissolution of plagioclase proceeds effectively to provide dissolved $\mathrm{Al}$ and $\mathrm{Si}$ in the porewater. In the lower part of the vessel, $\mathrm{pH}$ of the infused porewater increases to 5-6. Upon the downward transport of Al- and Sicontaining porewater, Al-rich clay mineral precipitates. After consumption of $\mathrm{Al}$ and $\mathrm{Si}$ in the porewater, $\mathrm{Mg}$-rich clay mineral forms in the lower part of the vessel. The produced clay mineals are consistent with Martian weathering profile.

Based on the measured $\mathrm{Al}$ contents in the porewater and results of rain/snow precipitation from a climate model for early Mars [4], we suggest that the observed Al-rich clay deposits on Mars can be generated in a short-term $\left(\sim 10^{3}\right.$ years) through infusion of sulfric acid surface water. The weathering profiles may have formed upon transient warming at locations where sulfuric acids accumulated.

[1] Murchie et al. (2009) J. Geophys. Res. 114, E00D06. [2] Bishop et al. (2008) Science 321, 830-833. [3] Zolotov and Mironenko (2016) Icarus 275, 203-220. [4] Wordsworth et al. (2015) J. Geophys. Res. Planets 120, 1201-1219. 